\title{
The effect of road safety education on the relationship between Driver's errors, violations and accidents: Slovenian case study
}

\author{
Darja Topolšek ${ }^{1 *}$ D, Dario Babić $^{2}$ and Mario Fiolić ${ }^{2}$
}

\begin{abstract}
One of the pillars of road safety strategies, in almost every country in the world, is training and education. Due to the diversity and different extents of evaluation methods, the influence of educational and training programs on traffic safety is still limited. The aim of this research is to evaluate the effect of the Slovenian educational program "I still drive, but I cannot walk". For this purpose 183 participants, divided into two groups: ones who participated in the program and others who did not, fulfilled the Driver Behaviour Questionnaire (DBQ) in order to identify their most common errors and violations. The results, based on the best model of multi-group moderator effect, indicate that the link between Violations and Accidents is significantly different between those who participated in the program and those who did not. This link is weaker among the respondents who participated in the program compared to others who did not. This may lead to the conclusion that the group of drivers who participated in the program has a "weaker" Violations resulting in accidents.
\end{abstract}

Keywords: Driver's education, DBQ, Traffic safety

\section{Introduction}

Road accidents represent a significant social problem since 25,500 people were killed on the roads of the European Union in 2016 with more than 135,000 injured [10]. The total damage of road accidents is very difficult to estimate as it does not only include the cost of treatment and material damage, but also indirect damages in the form of: reduction of job opportunities, loss of working ability, inability to perform daily activities, direct reproductive costs of medical or professional rehabilitation, indirect reproductive police costs, court proceedings, insurance companies, etc. Depending on the Member State, it is estimated that these losses amount from $1 \%$ to even $3 \%$ of gross domestic product [38].

For this reason, road safety is one of the key focuses of the European Commission, which adopts a new European Road Safety Action Program every ten years. The main

\footnotetext{
* Correspondence: darja.topolsek@um.si

'Department of Technical Logistics, Faculty of Logistics, University of Maribor, Celje, Slovenia

Full list of author information is available at the end of the article
}

task of the Program is to reduce the number of fatalities on EU roads. Since the overall road safety depends on the interaction of three main elements: human, road and vehicle, one can conclude that traffic accidents represent a failure of the whole traffic system (interaction between the three elements). For a long time, human error was most often considered as the main and more or less fatal cause of road safety problems since humans are, by nature, subject to errors. Although humans make a lot of errors, these errors are not always the true cause of accidents. Namely, a different phenomenon related to the road itself or the vehicle may trigger the human error and thus be the true cause of an accident. This is why the modern road safety strategies clearly differentiate the factors that truly cause accidents, whether they are human, environmental, vehicular, etc. Such a differentiation may lead to more diverse and efficient solutions directed toward preventing human errors by acting on their identified causes, and by promoting a better ergonomics of the driving system in accordance with human capacities and weaknesses [8]. 
In addition to the mentioned differentiation, training and education are one of the pillars of road safety strategies and solutions for increasing road safety. In almost every country in the world road safety education is, to a certain extent, part of formal education system. It is also a constituent part of initiatives, programs and activities outside the formal education. However, although there are plenty of road safety education programs, the number of those that are followed by detailed evaluation is rather limited [7]. Different and/or poor evaluation methods may be the reason why several studies failed to prove the positive outcomes of these programs [9, 19, 31, 33, 34, 36].

On the other hand, with better evaluation methods and research on drivers' education on road safety, recent studies $[21,30]$ showed statistically significant reduction in road accidents. The studies indicated that teens who underwent the education program were less likely to be involved in accidents during their first two years of driving, compared to the teens who did not go through the education. Based on the analysis of effectiveness of road safety education in Nebraska, the authors Shell et al. [30] concluded that the non-educated group was 1.22 times more likely to get in an accident than those who underwent the education program. In their analysis, authors took into account key demographic factors such as age, sex, race/ethnicity, urbanicity and household income.

A more large-scale study examined the safety performance of teen drivers who underwent the education program and those who did not [21]. The study was conducted in two stages. Firstly, a sample of teen drivers was surveyed prior to completing the educational program and their accidents and convictions were compared once they got their provisional license. In the second stage, historical records were used to examine the accidents and convictions of a much larger population of Oregon teens who had and had not completed the approved educational program [21]. The authors concluded that the safety effects of approved educational program are either neutral (based on the first part of the study) or cautiously optimistic (based on the results of the second part).

Since from the above mentioned one can conclude that there are gaps in the evaluation methods and different strategies used in the available literature, further research is needed in order to get better insight on the influence of educational programs on road safety. In order to develop efficient training and education activities, it is primarily necessary to identify common human errors and violations. A frequently used method for this is Driver Behaviour Questionnaire (DBQ), originally developed in Britain by [26].

The DBQ is based on the theoretical taxonomy of aberrant behaviours and represents a psychometric instrument and accident predictor. The main distinction between errors and violations is based on the assumption that they have different psychological origins and demand different modes of remediation. Errors are defined as "the failure of planned actions to achieve their intended consequences", while violations are "deliberate deviations from those practices believed necessary to maintain the safe operation of a potentially hazardous system" [26].

The main purpose of this research is to evaluate the DBQ factors used to develop the best model of multi-group moderator effect among drivers who attended the Slovenian educational program "I still drive, but I cannot walk" compared to those who did not attend the program. The program is organized by the Institute for Innovative Safe Driving Education "Vozim" which was founded on the initiative of young paraplegics/victims of road accidents. Since 2008, the Institute has been implementing a preventive program "I still drive, but I cannot walk", focused on future young drivers between the age of 15 and 22. An innovative interactive road safety program is based on personal stories of victims, injured in road traffic accidents, who through their own experience provide direct information related to the importance of safe driving and compliance with road traffic regulations. Through personal stories told by people injured in road traffic, young people get the insight into their life before the accident, the car accident and life after it. In this way, they become aware of the importance of safe and responsible driving and possible consequences if disregarding them. Young people therefore learn firsthand about the causes of traffic accidents, tips for safe driving and as well as the lives of the disabled and their "new life" after rehabilitation, thereby encouraging the destigmatization of physically handicapped individuals. Through the stimulated discussions and questions, participants actively shape the content of the lectures. In this way, participants and disabled persons have more personal contact and share more intimate details, which ultimately results in their connection on deeper level. With this, participants, get clear message that traffic accidents are real and do not happen just "to other people" but may also happen to them. Based on what they heard during program, young participants may "think twice" about what may happen before they engage in risky driving.

The main goal of this research is to evaluate how this unique approach affects driver's errors and violations and how they are connected to the frequency of traffic accidents caused by young drivers who participated in the program and those who didn't.

\section{Conceptual framework, survey and hypotheses}

Figure 1 shows the conceptual framework with the hypothesized model. The framework consists of twentyseven (27) items of the DBQ questionnaire, which are symbolized by variables DBQi, $\mathrm{i}=1,2,4 \ldots 28$ (3 is excluded 


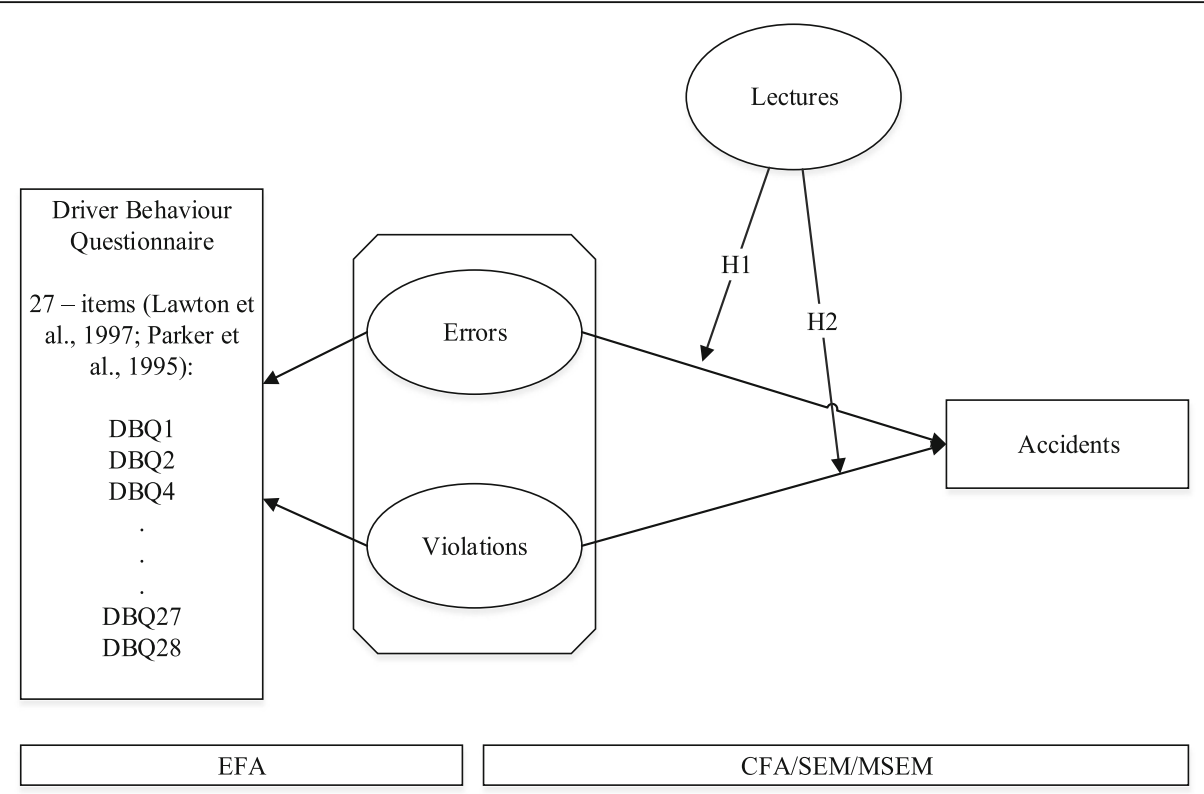

Fig. 1 The conceptual framework

based on recommendation of authors [16, 17, 24-26]). Two DBQ factors (Errors and Violations) and accidents are represented as the number of accident caused by participant.

The main aim of this framework is to evaluate the effect of Errors and Violations on the number of accidents caused by a participant. As mentioned in the introduction, the aim of this study is to evaluate the DBQ factors used to develop the best model of multi-group moderator effect among drivers who participated in the Slovenian road safety program "I still drive, but I cannot walk", compared to those who did not attend the program. In addition, the analysis of the impact of these behaviours on the number of accidents caused by the two studied groups is conducted. Based on this research gap the following two hypotheses were explored:

H1. The road safety education program "I still drive, but I cannot walk" has a moderation effect on the relationship between Errors and Accidents; this relationship is "weaker" for those who participated in the program than for those who did not.

H2. The road safety education program "I still drive, but I cannot walk" has a moderation effect on the relationship between Violations and Accidents; this relationship is "weaker" for those who participated in the program than for those who did not.

The main aim of this research is therefore to determine the difference between how Violations and Errors affect the Accidents depending on whether the driver participated in the Slovenian road safety program "I still drive, but I cannot walk", or not. The "weaker" relationship in this case means, that those who did participate road safety program may cause less accident derived from Errors/Violations than those who did not attend the program.

\subsection{Instruments}

The questionnaire was divided in two sections. The first part consisted of 27 driver behaviour questions that were selected from the previous versions of the DBQ $[16,17$, 24-26]. The questionnaire was designed to evaluate the effect of certain control variables on the behavioural factors. In this case it was used to evaluate the differences between "safe" driving behaviour depending on the participation in the education program. Respondents were asked to indicate how often they commit each of the violations or errors showed in Table 1, when driving a car on a 5-point Likert scale from "Never" to "Nearly all the time".

The second part contained demographic questions regarding age and gender as well as information related to the driving experience, their driving habits (how often do they drive a car: daily, weekly, monthly, yearly), estimated annual distance driven and accidents in the past years.

\subsection{Participants}

The data was collected over four week period in 2017 by means of online surveys. The sampling strategy was intended to gather data from two different driver groups. The first group consisted of people who had participated in the road safety educational program "I still drive, but I cannot walk". The second group was composed of young drivers (nearly the same age) who did not attend the education program.

In total 183 participants fully completed the questionnaire. Of that number, $54.6 \%$ were the drivers who 
Table 1 DBQ questionnaire

1. Hit something when reversing that you had not previously seen
2. Intending to drive to destination A, you "wake up" to find yourself on
the road to destination B
4. Get into the wrong lane approaching a roundabout or a junction
5. Queuing to turn left onto a main road, you pay such close attention
to the main stream of traffic that you nearly hit the car in front
6. Fail to notice that pedestrians are crossing when turning into a side
street from a main road
7. Sound your horn to indicate your annoyance to another road user
8. Fail to check your rear-view mirror before pulling out, changing
lanes, etc.
9. Brake too quickly on a slippery road or steer the wrong way in a skid
10. Pull out of a junction so far that the driver with right of way has to
stop and let you out
27. Underestimate the speed of an oncoming vehicle when overtaking
11. Disregard the speed limit on a residential road
12. Switch on one thing, such as the headlights, when you meant to
switch to something else, such as the wipers
an emerinst you
13. On turning left nearly hit a cyclist who has come up on your inside
14. Miss "Give Way" signs and narrowly avoid colliding with the traffic
having the right of way
15. Attempt to drive away from the traffic lights in third gear
16. Attempt to overtake someone that you had not noticed to be signalling
a right turn
17. Become angered by another driver and give chase with the intention
of giving him/her a piece of your mind
18. Stay in a motorway lane that you know will be closed ahead until
19. Forget where you left your car in a car park
20. Overtake a slow driver on the inside
21. Race away from traffic lights with the intention of beating the driver
nextead the signs and exit from a roundabout on the wrong road
23

participated in the program and $45.4 \%$ the ones who did not. The majority of the participants were female $(72.1 \%)$ between 20 and 29 years old (21.1\% below 20), and they all have valid driver's licence (35\% for less than 2 years and $34 \%$ from 2 to 5 years).

\subsection{Data analysis}

As mentioned before, the aim of the study is to evaluate the DBQ factors used to develop the best model of multi-group moderator effect among two groups of drivers and thus evaluate the efficiency of the educational program "I still drive, but I cannot walk". Therefore, we used the exploratory factor analysis in order to indetify the nature of the latent factors (constructs) and to estimate their indicator items loadings [13].

Using covariance-based structural equation modelling the DBQ variables and road accidents were carried in the modelling of moderated mediation in order to investigate the relationship between an independent variable and a dependent variable and the kind of the mediating variables. In order to model the moderating effect for latent construct, an alternative method was used for assessing the effect of moderator variable in the model in covariance-based structural equation modelling Multi-group CFA. The critical ratio difference test which represents the parameter estimate divided by its standard error; as such, it operates as a z-statistic in testing that the estimate is statistically different from zero was used. For the hypothesis to be rejected the test values needs to be $> \pm 1.96$ with the probability level of 0.05 .

\section{Results}

The descriptive statistics of the measured data was investigated with the emphasis on the analysis of normality because of disturbed accuracy of model validation if the data are non-normal [35]. Normality tests are usually conducted with the skewness index $(\mid$ SI $\mid<3)$ and kurtosis index $(|\mathrm{KI}|<7)$ of the data.

\subsection{Exploratory factor analysis}

The responses to the $27 \mathrm{DBQ}$ items were subjected to an exploratory factor analysis (EFA), using the Principal Axis Factoring (PAF) algorithm, with additional Promax rotation (and Kaiser normalization). PAF was our preferred method for estimation, given that it does not rely on the assumption of multivariate normality, which can definitely be treated as an advantage [11].

Different research about the DBQ questionnaire have implicated that the subsequent factor model can be articulated by four, three or two essential factors [2-6, 16, 22-24, 28, 29, 32].

The possibility that the factor analysis may be used without any concerns was tested by two tests: Kaiser-Meyer-Olkin KMO test and the Bartlett's test of sphericity (BTS) [13-15]. The BTS value was significant $\left(\chi^{2}=1225.173\right.$ with $\mathrm{df}=231$ and $\left.p<0.001\right)$, while the KMO value was $0.846>0.5$. According to the recommendation of some authors [12, 18, 27], the achieved BTS and KMO values imply that the EFA can be reliably conducted in further research.

For the factors extraction process, the principal axis factoring (PAF) algorithm with the Promax rotation was used. The Scree plot and Eigen value were inspected to determine the optimal number of factors. Both of them 
suggested the presence of only two factors. The two factors explained the $43.75 \%$ of the variance. According to [13], only those items which are significantly loaded on corresponding factors (loadings $>0.45$; communalities over 0.5 ) were retained in the model.

We labelled the first factor Errors because it contains items related to errors or lapses. The second factor was labelled Violations because of high loading items reflecting aggressive violation or Ordinary violations $[4,16,20]$.

Factor loadings of two-factor structure can be seen in Table 2 .

\subsection{Confirmatory factor analysis}

Confirmatory factor analysis (CFA) was performed in order to test the fit of the initial derived factor model to the exploratory factor analysis (EFA). The maximum likelihood (ML) method was used to estimate all model parameters at first. While estimating the parameters, the difference between the data-based covariance matrix and the model-implied covariance matrix was minimized [14]. The goodness of fit indicates proper fit of the model because all of fit measures are higher than threshold ranges: Normed fit index $(\mathrm{NFI}=0.913)$, Tucker-Lewis index $(\mathrm{TLI}=0.986)$, Comparative Fit Index $(\mathrm{CFI}=0.995)$, Root Mean Square Error of Approximation (RMSEA $=0.032)$, Standardized Root Mean Residual (SRMR =0.0402) (Byrne 2009). Convergent and discriminant validity were also tested. Both the adequate composite reliability and average variance extracted were inside the interval and it can be concluded that there are no validity concerns.

\subsection{Structural equation modelling results}

This study applies two variables, namely Errors and Violations, derived from the DBQ and a variable named Accident, representing the number of accidents caused by a participant. Maximum likelihood estimator in structural equation modelling was used to determine the probability values ( $p$-value) in order to identify the research hypothesis as the prior in the empirical study.

We first tested the global model, measuring the effect of Errors and Violations on Accidents (number of traffic accident caused by driver). This model fits well to the

Table 2 Two-factor solution with descriptive data and loadings

\begin{tabular}{|c|c|c|}
\hline Items & $\begin{array}{l}\text { Factor } 1 \\
\text { (Errors) }\end{array}$ & $\begin{array}{l}\text { Factor } 2 \\
\text { (Violations) }\end{array}$ \\
\hline Cronach Alpha & 0.834 & 0.760 \\
\hline$\%$ of Variance & 28.359 & 15.397 \\
\hline Cumulative \% & 28.359 & 43.756 \\
\hline DBQ22. Misread the signs and exit from a roundabout on the wrong road & 0.743 & \\
\hline DBQ14. Miss "Give Way" signs and narrowly avoid colliding with traffic having right of way & 0.645 & \\
\hline DBQ4. Get into the wrong lane approaching a roundabout or a junction & 0.638 & \\
\hline DBQ12. Switch on one thing, such as the headlights, when you meant to switch on something else, such as the wipers & 0.622 & \\
\hline DBQ13. On turning left nearly hit a cyclist who has come up on your inside & 0.598 & \\
\hline DBQ15. Attempt to drive away from the traffic lights in third gear & 0.512 & \\
\hline DBQ16. Attempt to overtake someone that you had not noticed to be signalling a right turn & 0.510 & \\
\hline DBQ19. Forget where you left your car in a car park & 0.501 & \\
\hline DBQ27. Underestimate the speed of an oncoming vehicle when overtaking & 0.497 & \\
\hline DBQ1. Hit something when reversing that you had not previously seen & 0.489 & \\
\hline DBQ9. Brake too quickly on a slippery road or steer the wrong way in a skid & 0.485 & \\
\hline DBQ26. Realise that you have no clear recollection of the road along which you have just been travelling & 0.470 & \\
\hline DBQ2. Intending to drive to destination A, you "wake up" to find yourself on the road to destination B & 0.464 & \\
\hline DBQ28. Disregard the speed limit on a motorway & & 0.655 \\
\hline DBQ21. Race away from traffic lights with the intention of beating the driver next to you & & 0.583 \\
\hline DBQ11. Disregard the speed limit on a residential road & & 0.575 \\
\hline DBQ18. Stay in a motorway lane that you know will be closed ahead until the last minute before forcing your way into the other lane & & 0.565 \\
\hline DBQ24. Cross a junction knowing that the traffic lights have already turned against you & & 0.537 \\
\hline DBQ20. Overtake a slow driver on the inside & & 0.531 \\
\hline DBQ7. Sound your horn to indicate your annoyance to another road user & & 0.529 \\
\hline DBQ23. Drive so close to the car in front that it would be difficult to stop in an emergency & & 0.506 \\
\hline DBQ25. Become angered by a certain type of a driver and indicate your hostility by whatever means you can & & 0.476 \\
\hline
\end{tabular}


data $\left(X^{2}=115.306 ; \quad \mathrm{df}=181 ; \quad \mathrm{GFI}=0.948 \quad \mathrm{NFI}=0.912\right.$; $\mathrm{CFI}=0.987$; $\mathrm{RMSEA}=0.021 ; \mathrm{SRMR}=0.042$ ). It was predicted that Driver who makes more Errors causes more traffic accidents, but this path has a significant and negative effect on Accidents $(-0.34, p<0.05)$. As predicted, Table 3 shows that Violations have significant and positive effect on Accidents $(0.294, p<001)$. The full model is shown in Table 3.

\subsection{Moderating structural equation modelling results}

After the measurement model has been validated, the next step was to assemble these constructs in the moderated structural equation modelling. The main problem of this research was focused on the difference between two groups of drivers. The first group consisted of drivers who participated in the road safety educational program "I still drive, but I cannot walk" and the second group of the ones that did not.

The moderator-mediator in the form of Structural Equation Modelling (SEM) was used to examine the interrelationship among the two mentioned groups.

In this case, the effect of Errors and Violations on Accidents upon a multi-group analysis is performed. The results indicate that the relationships in our model are different between the two groups in one case. The link between Violations and Accidents is significantly different between those who participated in the program "I still drive, but I cannot walk" and those who did not $\left(\mathrm{Z}=-1.313^{* *}\right)$ as shown in Table 4 . This link is stronger among the participants who did not participate in the program $(\beta=0.646, p<0.001)$ compared to the others who did $(\beta=0.252, p<0.05)$. This indicates that the drivers who participated in the program obey the traffic regulations and are more responsible when driving, meaning that they may violate the regulations less and thus cause less accidents. Other relationships do not present significant differences between the groups. Based on this, it can be concluded that the hypothesis $\mathrm{H} 2$ is verified, while the hypothesis $\mathrm{H} 1$ cannot be verified.

For analyzing possible differences between male and female participants the Multiple-Group Analysis was conducted. The results show that for both paths (Errors-Accidents and Violation-Accident) groups are not different at the model level as well as at the path level. This result implies that, even though with lower male sample, gender of participants did not affect the "strength" of the relationship between Errors-Violations

Table 3 Full model

\begin{tabular}{llllll}
\hline & Estimate & Std. error & Critical ratio & Probability \\
Accident $\leftarrow$ Errors & -0.342 & 0.252 & -1.356 & 0.048 \\
\hline Accident $\leftarrow$ Violations & 0.294 & 0.155 & 1.904 & 0.031 \\
\hline
\end{tabular}

Note: $N=183$ (unstandardized coefficients are reported)
Table 4 Critical ratios of comparison between groups

\begin{tabular}{|c|c|c|c|c|c|c|c|}
\hline \multirow{2}{*}{\multicolumn{3}{|c|}{ Construct relationship }} & \multicolumn{2}{|c|}{$\begin{array}{l}\text { DID participate } \\
\text { in the program }\end{array}$} & \multicolumn{2}{|c|}{$\begin{array}{l}\text { DID NOT } \\
\text { participate in } \\
\text { the program }\end{array}$} & \multirow[t]{2}{*}{ z-score } \\
\hline & & & Estimate & $p$ & Estimate & $p$ & \\
\hline ccident & $\leftarrow$ & Errors & -0.589 & 0.027 & -0.822 & $* * *$ & 0.418 \\
\hline ccident & $\leftarrow$ & Violations & 0.252 & 0.020 & 0.646 & $* * *$ & $-1.313^{* *}$ \\
\hline
\end{tabular}

$N=183$ (unstandardized coefficients are reported)

$\mathrm{N}_{\text {DID }}=100 ; \mathrm{N}_{\text {DID_NOT }}=83$

${ }^{* * *} p$-value $<0.01 ;{ }^{* *} p$-value $<0.05 ;{ }^{*} p$-value $<0.10$

and Accidents, i.e. there are no statistically significant differences between male and female participants.

\section{Discussion}

Educational programs represent one of the core road safety measures in most of the countries around the world. However, the efficiency of these programs and their positive effect on overall road safety is still unknown to a certain extent. One of the main reasons for this is the diversity of used strategies and evaluation methods. Nevertheless, recent studies [21, 30] show that with improved educational approaches and evaluation methods, relatively small but still statistically significant reduction in road accidents, involving drivers who attended the programs, is possible.

Based on the mentioned gaps and positive findings in the available literature, the main purpose of this research was to evaluate the efficiency of the Slovenian educational program "I still drive, but I cannot walk". The program is based on the personal contact between participants (young drivers) and disabled persons. In this way, young drivers, who do not have enough experience, firsthand hear and see what may happen with the risky driving. The aim of this paper was to evaluate how this unique approach affects driver's errors and violations and their connection to the frequency of traffic accidents caused by young drivers who participated in the program and those who didn't.

In order to identify common human errors and violations, the Driver Behaviour Questionnaire (DBQ) was used to examine the moderation effect of a variable, namely the participation in the program (categorical variable), in the relationship path between exogenous and endogenous constructs. This approach also allowed us to assess how well our conceptual model as a whole fits the data.

The test of a full model (regardless of whether they did/ did not participate in the program) measuring effect of Errors and Violations on Accidents showed that the relationship between driver's Errors and number of Accidents is significantly negative. This means that the drivers who make more errors do not cause more accidents. On the other hand, the drivers who make more Violations are more susceptible to cause traffic Accidents.

The moderator-mediator in the form of Structural Equation Modelling (SEM) was used in order to examine 
the interrelationship between the two analysed groups (drivers who participated in the program and those who did not). The results of the effect of Errors and Violations on Accidents based on the multi-group analysis show that the link between Violations and Accidents is "weaker" among the participants who participated in the program, compared to those who did not. This indicates that the drivers in the first group became more aware and responsible after the program. In other words, the participants who attended the Slovenian road safety program "I still drive, but I cannot walk" may violate traffic regulations less and thus cause less accidents compared to those who did not participated in the program. In addition, difference of gender was not found meaning that the relationship between Errors-Violations and Accidents is the same for male and females.

The limitation of this study is mainly related to the fact that data collection was conducted in a relatively short period after the educational program took place. In the future, after each education period the driving behavior of the participants who attended the education should be investigated in order to get bigger dataset and stronger proof of here presented results. Also, the driving behavior of the participants investigated in this study should be periodically checked in longer time period, i. e. with the increase of their experience. In that way the long-term effect of the program may be determined since it is known that driving experience is negatively correlated to the risk of accidents and injuries [1, 37].

The relationship between driver's Errors, Violations and the number of Accidents should be analysed in a longer period of time in order to get a deeper insight on the effect of educational programs on the drivers' behaviour.

\section{Conclusion}

A Driver Behaviour Questionnaire (DBQ) was used to determine most common errors and violations and to develop model of multi-group moderator effect among drivers who attended the Slovenian educational program "I still drive, but I cannot walk" compared to those who did not attend the program. Results of a multi-group analysis showed indicated that the relationships between Violations and Accidents are different between the two groups (drivers who participated in the program and those who did not), indicating that the drivers who participated in the program may cause less Violations resulting in accidents. Results also indicate that the relationships between Errors and Accidents do not present significant differences between the groups. From all the above, it may be concluded that the program had a positive effect on the behaviour of young people who participated in it, meaning that they may ultimately be more responsible drivers and thus cause less accidents. These results show that more personal contact based on the empathy, emotions and mutual understanding may be more efficient in increasing awareness of the young drivers. Ultimately, this study represents a positive methodology for evaluation of a road safety educational program and as such provides significant scientific contribution.

\section{Acknowledgements \\ Not applicable. \\ Funding \\ There was no funding \\ Availability of data and materials \\ The datasets generated and/or analyzed during the current study are not publicly available because of some personal data included in database but are available from the corresponding author on reasonable request.}

Authors' contributions

DT prepared: the idea and research gap, a survey (prepared a survey, cooperated with the Institute for Innovative Safe Driving Education "Vozim"), the SEM model, and the results. DB prepared: summary, literature review, discussion and conclusion. All authors read and approved the final manuscript.

Competing interests

The authors declare that they have no competing interests.

\section{Publisher's Note}

Springer Nature remains neutral with regard to jurisdictional claims in published maps and institutional affiliations.

\section{Author details}

${ }^{1}$ Department of Technical Logistics, Faculty of Logistics, University of Maribor, Celje, Slovenia. ${ }^{2}$ Department of Traffic Signalling, Faculty of Transport and

Traffic Sciences, University of Zagreb, Zagreb, Croatia.

Received: 24 August 2018 Accepted: 30 January 2019

Published online: 12 March 2019

References

1. Ballesteros, M. F., \& Dischinger, P. C. (2002). Characteristics of traffic crashes in Maryland (1996 1998): Differences among the youngest drivers. Accid Anal Prev, 34(3), 279-284. https://doi.org/10.1016/S0001-4575(01)00023-9.

2. Bener, A., et al. (2013). A cross "ethnical" comparison of the driver behaviour questionnaire (DBQ) in an economically fast developing country. Global J Health Sci, 5(4), 165-175. https://doi.org/10.5539/gjhs.v5n4p165.

3. Conner, M., \& Lai, F. (2005). Evaluation of the effectiveness of the National Driver Improvement Scheme. Road safety research report, no. 64. London: Department for Transport.

4. Cordazzo, S. T. D., Scialfa, C. T., \& Ross, R. J. (2016). Modernization of the driver behaviour questionnaire. Accid Anal Prev, 87, 83-91. https://doi.org/10. 1016/j.aap.2015.11.016

5. De Winter, J. C. F., \& Dodou, D. (2010). The driver behaviour questionnaire as a predictor of accidents: A Metaanalysis. J Saf Res, 41(6), 463-470. https:// doi.org/10.1016/j.jsr.2010.10.007.

6. De Winter, J. C. F., Dodou, D., \& Stanton, N. A. (2015). A quarter of a century of the DBQ: Some supplementary notes on its validity with regard to accidents. Ergonomics, 58(10), 1-25. https://doi.org/10.1080/00140139.2015.1030460.

7. Dragutinovic, N., \& Twisk, D. (2006). The effectiveness of road safety education. Netherlands: Institute for Road Safety Research.

8. Elslande, P., Naing, C., \& Engel, R. (2008). Analyzing human factors in road accidents. TRACE WP5 Summary Report Available at: http://www.transportresearch.info/sites/default/files/project/documents/20130620_104810_ 50767 tracewp5d55v2.pdf.

9. Engstrom, I. et al. 2003.Young Novice Drivers, Driver Education and Training; Literature Review, VTI-Rapport 491A; Swedish National Road and Transport Research Institute: Linköping, Sweden. 
10. European Commision. 2017. Road Safety Statistics. Available at: http:// europa.eu/rapid/press-release_MEMO-17-675_en.htm. (04/05/2017).

11. Fabrigar, L. R., Wegener, D. T., MacCallum, R. C., \& Strahan, E. J. (1999). Evaluating the use of exploratory factor analysis in psychological research. Psychol Methods, 4(3), 272-299. https://doi.org/10.1037/1082-989X.4.3.272.

12. Frohlich, M. T., \& Westbrook, R. (2001). Arcs of integration: An international study of supply chain strategies. J Oper Manag, 19(2), 185-200. https://doi. org/10.1016/50272-6963(00)00055-3.

13. Hair, J. F., Black, W. C., Babin, B. J., \& Anderson, R. E. (2010). Multivariate Data Analysis (p. 816). Prentice Hall.

14. Hoyle, R. H. (2012). Handbook of structural equation modeling (p. 740). The Guilford Press.

15. Kline, R. B. (2005). Principles and practice of structural equation modeling (2th ed.p. 425). The Guilford Press.

16. Lajunen, T., Parker, D., \& Summala, S. (2004). The Manchester driver behaviour questionnaire: A cross-cultural study. Accid Anal Prev, 36(2), 231238. https://doi.org/10.1016/S0001-4575(02)00152-5.

17. Lawton, R., et al. (1997). Predicting road traffic accidents: The role of social deviance and violations. Br J Psychol, 88(2), 249-262. https://doi.org/10.1111/ j.2044-8295.1997.tb02633.x.

18. Li, J., et al. (2013). Chinese version of the nursing Students' perception of instructor caring (C-NSPIC): Assessment of reliability and validity. Nurse Educ Today, 33(12), 1482-1489. https://doi.org/10.1016/j.nedt.2013.05.017.

19. Lonero, L., Mayhew, D.R. 2010. Large-Scale Evaluation of Driver Education Review of the Literature on Driver Education Evaluation: 2010 Update. AAA Foundation for Traffic Safety: Washington, DC, USA.

20. Martinussen, L. M., et al. (2013). Age, gender, mileage and the DBQ: The validity of the driver behavior questionnaire in different driver groups. Accid Anal Prev, 52, 228-236. https://doi.org/10.1016/j.aap.2012.12.036.

21. Mayhew, D., et al. (2017). Evaluation of beginner driver education in Oregon. Safety 3, (1), 9. https://doi.org/10.3390/safety3010009.

22. Newnam, S., \& Von Schuckmann, C. (2012). Identifying an appropriate driving behaviour scale for the occupational driving context: The DBQ vs. the ODBQ Saf Sci, 50(5), 1268-1274. https://doi.org/10.1016/.jssci.2011.12.009.

23. Nordfjærn, T., \& Şimşekoğlu, O. (2014). Empathy, conformity, and cultural factors related to aberrant driving behaviour in a sample of urban Turkish drivers. Saf Sci, 68, 55-64. https://doi.org/10.1016/.jsci.2014.02.020

24. Özkan, T., et al. (2006). Cross-cultural differences in driving Behaviours: A comparison of six countries. Transport Res F: Traffic Psychol Behav, 9(3), 227242. https://doi.org/10.1016/j.trf.2006.01.002.

25. Parker, D., Reason, J. T., Manstead, A. S. R., \& Stradling, S. G. (1995). Driving errors, driving violations and accident involvement. Ergonomics, 38(5), 10361048. https://doi.org/10.1080/00140139508925170.

26. Reason, J., et al. (1990). Errors and violations on the roads: A real distinction? Ergonomics, 33(10-11), 1315-1332. https://doi.org/10.1080/ 00140139008925335

27. Sahin, M., et al. (2013). A structural equations model for assessing the economic performance of high-tech entrepreneurs. In R. Capello \& T. P. Dentinho (Eds.), Globalization trends and regional development (p. 48).

28. Salmon, P. M., et al. (2010). Managing error on the open road: The contribution of human error models and methods. Saf Sci, 48(10), 12251235. https://doi.org/10.1016/j.ssci.2010.04.004.

29. Senserrick, T. M., \& Swinburne, G. C. (2001). Evaluation of an insight drivertraining program for young drivers. Report no. 186. Victoria: Monash University Accident Research Centre.

30. Shell, D. F., et al. (2015). Driver education and teen crashes and traffic violations in the first two years of driving in a graduated licensing system. Accid Anal Prev, 82, 45-52. https://doi.org/10.1016/j.aap.2015.05.011.

31. Simpson, H. M. (2003). The evolution and effectiveness of graduated licensing. I Saf Res, 34(1), 25-34.

32. Sümer, N. Ayvașik, B. Er. N., Özkan, T. 2001. Role of Monotonous Attention in Traffic Violations, Errors, and Accidents. In Proceedings of the First International Driving Symposium on Human Factors in Driver Assessment, Training and Vehicle Design, p. 167-173. Aspen.

33. Thomas, F.D., III, Blomberg, R.D., Donald, L., Fisher, D.L. 2012. A Fresh Look at Driver Education in America. Report No. DOT HS 811 543. National Highway Traffic Safety Administration: Washington, DC, USA.

34. Vernick, J. D., et al. (1999). Effects of high school driver education on motor vehicle crashes, violations, and licensure. Am J Prev Med, 16(1), 40-46. https://doi.org/10.1016/S0749-3797(98)00115-9.
35. Weston, R., \& Gore, P. A. (2006). A brief guide to structural equation modeling. Couns Psychol, 34(5), 719-751. https://doi.org/10.1177/ 0011000006286345.

36. Williams, A., Preusser, D., \& Ledingham, K. (2009). Feasibility study on evaluating driver education curriculum. In National Highway Safety Administration. Washington, DC: USA.

37. Wong, T. W., Phoon, W. O., Lee, J., Yio, I. P., Fung, K. P., \& Smith, G. (1990). Motorcyclist traffic accidents and risk factors: A Singapore study. Asia Pac J Public Health, 4(1), 34-38. https://doi.org/10.1177/101053959000400106.

38. World Health Organization. 2017. Road Traffic Injuries. Available at: http:// www.who.int/mediacentre/factsheets/fs358/en/. (27/12/2016).

\section{Submit your manuscript to a SpringerOpen ${ }^{\circ}$ journal and benefit from:}

- Convenient online submission

- Rigorous peer review

- Open access: articles freely available online

- High visibility within the field

- Retaining the copyright to your article

Submit your next manuscript at $\boldsymbol{\nabla}$ springeropen.com 